\title{
Costs of moderate to severe chronic pain in primary care patients - a study of the ACCORD Program
}

This article was published in the following Dove Press journal:

Journal of Pain Research

7 July 2014

Number of times this article has been viewed

\author{
Lyne Lalonde ${ }^{1-4}$ \\ Manon Choinière ${ }^{3,5}$ \\ Élisabeth Martin ${ }^{2,3}$ \\ Djamal Berbiche $e^{2,3}$ \\ Sylvie Perreault ${ }^{1,6}$ \\ David Lussier ${ }^{7-9}$
}

'Faculty of Pharmacy, Université de Montréal, Montreal, QC, Canada; 2Équipe de recherche en soins de première ligne, Centre de santé et de services sociaux de Laval, Laval, QC, Canada; ${ }^{3}$ Centre de recherche du Centre hospitalier de l'Université de Montréal (CRCHUM), Montreal, QC, Canada; ${ }^{4}$ Sanofi Aventis Endowment Chair in Ambulatory Pharmaceutical Care, Université de Montréal and Centre de santé et de services sociaux de Laval, QC, Canada; ${ }^{5}$ Department of Anesthesiology, Faculty of Medicine, Université de Montréal, Montreal, QC, Canada; ${ }^{6}$ Sanofi Aventis Endowment Research Chair in Optimal Drug Use, Université de Montréal, Montreal, QC, Canada; ${ }^{7}$ Institut universitaire de gériatrie de Montréal, Montreal, QC, Canada; ${ }^{8}$ Division of Geriatric Medicine and Alan-Edwards Centre for Research on Pain, McGill University, Montreal, QC, Canada; ${ }^{9}$ Department of Medicine, Faculty of Medicine, Université de Montréal, Montreal, QC, Canada

Correspondence: Lyne Lalonde Centre de recherche du Centre hospitalier de l'Université de Montréal, 850 Saint-Denis Street, Tour SaintAntoine, Room S03.436, Montreal, Quebec, H2X 0A9, Canada $\mathrm{Tel}+|5| 48908000$ ext I549|

$\mathrm{Fax}+|5| 44127038$

Email lyne.lalonde@umontreal.ca
Background: The economic burden of chronic noncancer pain $(\mathrm{CNCP})$ remains insufficiently documented in primary care.

Purpose: To evaluate the annual direct health care costs and productivity costs associated with moderate to severe CNCP in primary care patients taking into account their pain disability.

Materials and methods: Patients reporting noncancer pain for at least 6 months, at a pain intensity of 4 or more on a 0 (no pain) to 10 (worst possible pain) intensity scale, and at a frequency of at least 2 days a week, were recruited from community pharmacies. Patients' characteristics, health care utilization, and productivity losses (absenteeism and presenteeism) were documented using administrative databases, pharmacies' renewal charts, telephone, and self-administered questionnaires. Patients were stratified by tertile of pain disability measured by the Brief Pain Inventory questionnaire.

Results: Patients (number $=483$ ) were, on average, 59 years old, mainly women $(67.5 \%)$, and suffered from CNCP for a mean of 12 years at an average pain intensity of $6.5 \pm 1.9$. The annual direct health care costs and productivity costs averaged CAD $\$ 9,565( \pm \$ 13,993)$ and CAD $\$ 7,072$ $( \pm 11,716)$, respectively. The use of complementary health care services accounted for almost $50 \%$ of the direct health care costs. The mean adjusted total direct health care costs (considering pain-related hospitalizations only) and productivity costs increased with more pain disability: low disability, CAD \$12,118; moderate, CAD \$18,278; and severe, CAD \$19,216; $P=0.001$.

Conclusion: The economic burden of CNCP is substantial and increases with the level of pain disability, which suggests the need for and potential benefits of improving CNCP management through specific and adapted treatment plans targeting the impact of pain on daily functioning.

Keywords: noncancer chronic pain, primary care, cohort study, direct health care costs, productivity costs, Brief Pain Inventory

\section{Introduction}

Chronic noncancer pain (CNCP) is defined by the International Association for the Study of Pain as a pain persisting beyond the normal healing time for a specific illness or injury. ${ }^{1}$ It is estimated that more than $25 \%$ of the Canadian population is affected by $\mathrm{CNCP}, 2,3$ a prevalence that tends to increase in our aging society. ${ }^{4}$ Based on four European studies published between 1991 and 2002, Ospina and Harstall ${ }^{5}$ estimated the prevalence of chronic pain to be $35.5 \%$. Affected individuals report lower quality of life, ${ }^{6}$ experience interferences in their daily activities ${ }^{4,7}$ and are at higher risk of suffering from depression and anxiety disorders, ${ }^{4,8}$ sleep problems, ${ }^{7}$ and additional comorbid conditions. ${ }^{9}$ 
CNCP is associated with substantial direct health care costs. In Quebec (Canada), the annual direct health care costs associated with rheumatoid arthritis, fibromyalgia, and painful neuropathic disorders are estimated to average CAD \$10,287 ( $\pm \$ 12,728$ [2002 values]; \$12,257 [2011 values]), ${ }^{10} \mathrm{CAD}$ $\$ 4,065$ ( $\pm \$ 6,798$ [2007 values]; \$4,339 [2011 values]), ${ }^{11}$ and CAD \$4,163 ( $\pm \$ 7,536$ [2002 values]; \$4,960 [2011 values]) ${ }^{12}$ per patient, respectively. Individuals with CNCP make more physician visits (mean of 12.9 visits per year versus 3.8 visits per year) and have longer hospital stays (mean of 3.9 days versus 0.7 days) than individuals without it. ${ }^{13}$

Chronic pain also causes substantial productivity losses arising from work absences (absenteeism) and reduced productivity at work (presenteeism). ${ }^{8}$ A Canadian survey revealed that individuals with $\mathrm{CNCP}$ missed an average of 9.3 (95\% confidence interval [CI]: 4.7-13.7) workdays annually due to their pain, a number rising to 16.0 (95\% CI: 5.1-26.9) among individuals with severe pain. ${ }^{2}$ In Australia, the productivity costs associated with $\mathrm{CNCP}$ are estimated to amount to $\mathrm{AU} \$ 5.1$ billion annually. ${ }^{14}$

Pain-related direct health care costs and productivity costs yield considerable global societal costs. Total CNCP expenditures represent more than 3\% of Finland's gross national product ${ }^{15}$ and US \$2.1 million per employer annually (1998 values) in the United States. ${ }^{16}$ More severe pain disability seems to be associated with higher societal costs. Patients with arthritis and rheumatism reporting more disability incurred higher direct health care ${ }^{17,18}$ and productivity costs. ${ }^{19,20}$ In the United States, when these costs are considered, the total annual cost of pain was greater than the annual costs of treating heart disease, cancer, and diabetes respectively. ${ }^{21}$

Although the vast majority of CNCP patients are followed-up in primary care, ${ }^{8}$ most studies have evaluated the economic burden of CNCP in patients recruited in specialized clinics. ${ }^{18,22-24}$ The objective of this project was, therefore, to describe the direct health care and productivity costs associated with $\mathrm{CNCP}$ among primary care patients. Patients with various diagnoses were considered and the costs were described as a function of their pain disability.

\section{Materials and methods Study design}

As part of the ACCORD Program (Application Concertée des COnnaissances et Ressources en Douleur), a knowledge translation research program in the field of $\mathrm{CNCP}$, a cohort study was conducted (one submitted paper is accepted for publication). ${ }^{25,26}$ In this cohort study, individuals with CNCP having an active analgesic prescription from a primary care physician were recruited from May 2009-January 2010 in community pharmacies. Patients completed a structured telephone interview and a self-administered questionnaire. Governmental administrative databases, the Régie de l'assurance maladie du Québec (RAMQ; Quebec health insurance board; QC, Canada) and the Maintenance et exploitation des données pour l'étude de la clientèle hospitalière (MED-ÉCHO - a hospitalization database), as well as community pharmacies' renewal charts were used to document health care use and costs in the year preceding the recruitment. Ethical approvals were obtained from the Comité scientifique et d'éthique de la recherche of the Centre de santé et de services sociaux de Laval (Laval, QC, Canada) and from the Commission d'accès à l'information (QC, Canada). Each patient signed an informed consent form and received a financial compensation of $\$ 25$ for completing the questionnaires. Pharmacists received a financial compensation of $\$ 50$ for every consenting patient.

\section{Study population}

The study was conducted in the Réseau universitaire intégré de santé de l'Université de Montréal (Montreal, QC, Canada), which encompasses six areas in the province of Quebec (Canada): Mauricie et Centre du Québec; Laval; Montréal; Laurentides; Lanaudière; and Montérégie, representing more than $40 \%$ of the population in this province. Based on the Quebec Health Ministry's atlas, 513 community pharmacies were identified in this territory. ${ }^{27}$ Among those, a random sampling stratified by region and weighted by the number of pharmacies located within each region was done. To recruit 60 pharmacies, selected pharmacies were sequentially contacted until the target numbers of pharmacies were reached in each region. To recruit 600 patients, each pharmacy had to identify between 10 and 15 consecutive and potentially eligible patients. During the course of the study, additional pharmacies were invited to participate, so as to compensate for those that did not recruit the expected number of patients.

To be eligible, patients had to: 1 ) be $\geq 18$ years of age; 2 ) report suffering from noncancer pain for at least 6 months and for a minimum of 2 days per week; 3$)$ rate their average pain in the past 7 days as $\geq 4$ on a $0-10$ intensity scale $(0=$ no pain; $10=$ worst possible pain) ${ }^{28} 4$ ) have an active analgesic prescription from a primary care physician; and 5) speak and read French or English. Patients reporting migraine as the only source of pain and those unable to provide informed consent were not eligible. The Canadian Pain Society and 
the World Health Organization define chronic pain as a pain lasting 6 months or more..$^{29,30}$ This definition is currently used in research. ${ }^{31}$ In order to ensure that patients' pain had some impact on various aspects of their daily functioning, only those who reported pain at least 2 days a week were selected.

\section{Direct health care and productivity costs} Direct health care costs

Direct health care costs, expressed in Canadian dollars, were estimated for each participant based on the health care resources used in the year preceding the recruitment.

All outpatient physician visits, as well as tests and interventions (related and unrelated to $\mathrm{CNCP}$ ), were documented from the RAMQ database. In this database, a service code is assigned to each of these components, along with the specialty of the professional consulted, the date, the site, and the amount reimbursed by the RAMQ, which was used to estimate the cost of the services. A pain specialist (DL) reviewed all tests and interventions provided to cohort patients in order to identify those related to CNCP.

All visits to emergency rooms (ER) were considered. Costs of these visits were documented from the RAMQ database and they included the costs of the visit, tests and interventions, and physician consultations. For each ER visit, a unitary cost of CAD \$270.54 (2011 values) was considered. This cost corresponds to the average provincial cost per ER according the Quebec Health Ministry (Direction de l'allocation des ressources, unpublished data) and accounts for expenses incurred by the health care institution itself, including overheads and consumables. The costs of physician consultation(s), test(s), and intervention(s) provided during the ER stay were those paid by the RAMQ during the year preceding the recruitment (May 2008-January 2009).

All hospitalizations and those related, or possibly related, to $\mathrm{CNCP}$ were considered. Hospitalizations were documented from the MED-ÉCHO database, where information regarding the admission date, the primary and secondary diagnoses, the length of stay, and the site are recorded. The hospitalization costs included those of the hospital stay, physician visits, tests, and interventions. The cost of hospital stay represents a per diem cost of CAD \$948.73 (2011 values) according the Quebec Health Ministry (Direction de l'allocation des ressources, unpublished data), including overheads and consumables. This cost is the mean provincial cost per day of hospitalization, and it accounts for expenses related to the costs of nursing care, laboratory tests, medications, laundry, food, administration, and maintenance. Physician visit and test/intervention costs provided during hospitalizations were documented from the RAMQ database and corresponded to those reimbursed by the RAMQ from 2008-2009. The primary and secondary diagnostic codes associated with the hospitalizations were reviewed by a pain specialist (DL) (see Table S1) to identify those related or possibly related to $\mathrm{CNCP}$.

The use of nonpharmacological health care services was documented during the telephone interview by asking patients, "Now, I will read a list of different types of therapy that can be used to relieve pain. Please stop me each time I name a therapy you have used in the past." Overall, 23 therapies were enumerated: relaxation/breathing techniques; meditation; hypnosis; visualization; individual distraction; individual psychotherapy; group psychotherapy; self-help support group; physiotherapy; occupational therapy; hydrotherapy/ hot bath/aqua therapy; electrostimulation; intramuscular stimulation; ultrasounds; biofeedback; acupuncture; massotherapy; chiropractic; osteopathy; therapeutic touch; reflexology; Reiki; and magnet therapy. When patients identified a therapy that they had employed, the interviewer then asked them, "Have you used it in the past 6 months?" and if yes, "How frequently did you use it in the past 6 months? Every day, a few times every week, a few times every month, or a few times every year?" Those frequencies were translated into actual numbers of annual visits; every day $=260$ (annual number of weekdays); a few times every week =104; a few times every month $=24$; and a few times every year $=2$. The costs of each visit corresponded to the mean cost per visit in the Montreal area (QC, Canada) as a function of the type of professional consulted, and it varied between CAD \$45 and CAD $\$ 90$ (2007 values). ${ }^{32}$

Prescribed analgesics dispensed 1 year prior to the recruitment were documented from the RAMQ database or from pharmacies' dispensing charts; the latter allowed for the documentation of pharmacologic treatments of individuals not insured by the RAMQ for their medications. For each analgesic prescription (new and renewals), the following information was recorded: date of dispensation; common drug denomination; form; dosage; and quantity. Analgesics included acetaminophen, nonsteroidal antiinflammatory drugs, antidepressants, anticonvulsants, muscle relaxants, opioids, antiretroviral therapy, disease-modifying antirheumatic drugs, and antirheumatic biologic agents. Only antidepressants and anticonvulsants recommended for pain treatment were taken into account (see Table S2), ${ }^{33,34}$ and they were documented for patients not reporting depression or epilepsy. Antiretrovirals were those recommended to treat 
zona-related pain ${ }^{35}$ (valacyclovir, famciclovir, acyclovir). Prescribed medications to prevent or control the gastrointestinal adverse effects that are frequently reported with analgesics were also documented (laxatives, antacids, gastroprotectants, and antiemetics). The costs of each medication corresponded to those reimbursed by the RAMQ (List of Medications $2011)^{36}$ based on the form and the dosage of each product. The pharmacist's fee for each medication dispensed was also considered. For patients insured by the RAMQ, we used the actual dispensing fee paid by the RAMQ. For patients not insured by the RAMQ, a fee of CAD \$7.87, which corresponds to the mean dispensing fee paid by the RAMQ in 2011, was assumed.

To document over-the-counter medications used to treat pain and adverse effects associated with analgesics, patients were asked during the telephone interview: "In the past 6 months, have you taken over-the-counter medications or natural products for pain and for drug-related side effects such as constipation, heartburn, and nausea or vomiting?" The frequency of use was described in terms of every day, a few times every week, a few times every month, and a few times every year, and was later translated into annual numbers of daily recommended doses: every day $=365$; a few times every week $=104$; a few times every month $=24$; and a few times every year $=2$. Unitary costs were estimated using the McKesson database ${ }^{37}$ (McKesson distributes medications to more than 6,000 community pharmacies in Canada). Daily dosages represented the minimum recommended daily doses of each specific product in the Vigilance Santé Program ${ }^{38}-$ a computerized program that is frequently used in community pharmacies.

\section{Productivity costs}

Productivity costs, described in terms of absenteeism and presenteeism, were solely considered for individuals who were currently employed at the time of the interview (fullor part-time job), and for those who were on temporary or permanent disability; they were not considered for unemployed individuals, nor for those who were retired. This information was assessed during the telephone interview, as participants had to choose one of the enumerated choices, which included full- and part-time work and permanent and temporary disabilities.

Absenteeism was documented during the telephone interview using the following question: "In the past 6 months, how many days of work did you miss because of your pain or medical appointment, or treatment for you pain?" To evaluate the annual costs of absenteeism, the reported number of days absent from work due to pain in the past 6 months was multiplied by 2 . For individuals with a full- or part-time job, productivity costs were calculated by multiplying the annual number of workdays missed by the mean Canadian hourly wage (CAD \$23.06 [2011 values]) $)^{39}$ and the mean number of hours worked daily (7.24 hours). ${ }^{40}$ For individuals on temporary or permanent disability, productivity costs were calculated by multiplying the annual number of workdays missed by the minimum wage as estimated in 2011:41 CAD $\$ 9.65 /$ hour; 8 hours/day. For individuals on temporary disability, the annual number of workdays missed represented the reported number of days absent from work due to pain in the past 6 months, multiplied by 2 , and for individuals on permanent disability, it corresponded to 260 (annual number of weekdays absent).

As for absenteeism, presenteeism was only estimated for individuals with a full- or part-time job and for those on permanent or temporary disability. Based on the method described by $\mathrm{Hu}$ et al, ${ }^{42}$ presenteeism was evaluated during the telephone interview using the following question: "In the past 6 months, what percentage of your productivity at work did you lose, on average, because of your pain? Please answer using a scale from $0 \%$ to $100 \%$ where $0 \%$ means 'no loss in productivity' and 100\% means the 'loss of all productivity'." Presenteeism was estimated by multiplying the time lost due to pain (the number of workdays with pain by the percent of productivity lost on those days), by the number of hours worked per day ( 7.24 hours $)^{40}$ and by the hourly wage (CAD \$23.06 [2011 values]). ${ }^{39}$

\section{Pain disability}

The impact of pain on daily functioning was assessed in the telephone interview using the interference items of the modified Brief Pain Inventory (BPI). The BPI is a widely used instrument in pain research and its psychometric qualities are well documented. ${ }^{43,44}$ It includes ten interference items. For each one, patients are asked to rate, on a $0-10$ scale $(0=$ does not interfere, $10=$ interferes completely $)$, the extent to which pain interferes with various aspects of their daily living including general activity, walking ability, mood, normal work, relations with other people, sleep, enjoyment of life, self-care, recreational activities, and social activities. A global BPI score is derived by taking the average rating on the ten items. ${ }^{43}$

\section{Patients' characteristics}

Sociodemographic and pain characteristics were documented with the self-administered questionnaire and 
telephone interview. The characteristics of pain included its duration (time since onset) and frequency in the past week. The circumstances surrounding the onset of the pain and its location(s) were also recorded. Pain diagnoses were based on patients' self-reports using the following question during the telephone interview: "I will read a list of diagnoses that can be at the origin of your pain. Please stop me each time I read a diagnosis corresponding to your condition." The list included ten diagnoses, and patients had the opportunity to report diagnoses not included in the list. Diagnoses were then grouped into eight main categories: 1) back pain; 2) neck pain; 3) fibromyalgia; 4) neuropathic pain; 5) visceral pain; 6) inflammatory arthritic pain (for example, rheumatoid arthritis); 7) degenerative arthritic pain (for example, osteoarthritis); and 8) tendinitis, bursitis, capsulitis, and epicondylitis. The impact of pain on sleep was investigated using the Chronic Pain Sleep Inventory, ${ }^{45}$ while depression and anxiety levels were measured using the Hospital Anxiety and Depression Scale. ${ }^{46}$ Depression and anxiety scores were rated as "absent" (scores $\leq 7$ ), "uncertain" ( scores between 8-10), or "probable" (scores $\geq 11$ ). The presence of comorbid conditions was assessed through the Charlson Comorbidity Index, an instrument that takes into account the number and seriousness of comorbid diseases. ${ }^{47}$

\section{Data analyses}

Annual costs were described on the basis of a societal perspective, in terms of direct health care and productivity costs. They were adjusted to 2011 Canadian dollar values based on the consumer price index (Statistics Canada, Ottawa, ON, Canada). ${ }^{48}$ Taking into account the resources used in the year preceding the recruitment, the costs of hospitalizations, the ER visits, the outpatient physician, and other health care professional visits, pharmacotherapy (prescribed and over-the-counter medications that were used to treat pain and adverse effects associated with analgesic medications), as well as the costs associated with productivity loss due to absenteeism and presenteeism, were computed for each patient. Thereafter, the total direct health care costs and the costs associated with productivity loss were computed. The mean ( \pm standard deviation) of these costs was computed for the entire cohort, as well as by three subcohorts defined by the tertile of the global BPI scores labeled as mild, moderate, and severe disability. The statistical significance of the between subcohort differences was estimated using a univariate linear regression model and chi-square statistics for continuous (for example, annual health care resource use and health care costs) and categorical variables, respectively.
Multivariate linear regression models were also developed to predict the costs as a function of the BPI tertile after adjusting for the following confounders: age; $;^{12,17} \mathrm{sex} ;{ }^{12}$ duration of pain; ${ }^{17,49}$ and the Charlson comorbidity score. ${ }^{22,23,50,51}$ All variables associated with at least a $10 \%$ change in the cost estimate in the univariate analyses were included in the final multivariate model. Given the lack of precision in the identification of hospitalizations related to CNCP, allcause hospitalizations were considered in this analysis. In a secondary analysis, only pain-related hospitalizations were reported. For each BPI tertile, the mean cost and its 95\% CI were calculated. Gamma transformations of costs were employed in all cases. ${ }^{52}$ Statistical analyses were carried out using SPSS Statistics Base 19.0 for Windows ${ }^{\circledR}$ (IBM Corporation, Armonk, NY, USA) and SAS ${ }^{\circledR}$ Software (version 9.1; SAS Institute Inc., Cary, NC, USA).

\section{Results}

Between May and October 2009, a total of 296 community pharmacies were invited to participate; 84 pharmacies were recruited and 70 completed the study and recruited patients (Figure 1). Between May 2009 and January 2010, pharmacists referred 609 potentially eligible patients, of whom 38 were ineligible and 85 refused to participate. Data from the community pharmacies' renewal charts and from the RAMQ and the MED-ÉCHO databases were available for all participants (number $[\mathrm{n}]=486$ ). Telephone interviews and self-administered questionnaires were completed by 485 and 483 individuals, respectively. Based on the BPI tertile scores, three subcohorts were created and included 483 individuals: mild disability, BPI scores between 0.0-4.30 $(n=165)$; moderate disability, scores between 4.31-6.40 $(\mathrm{n}=160)$; and severe disability, scores between 6.41-10.0 $(n=158)$.

As reported in Table 1, participants were middle aged (mean age: $59 \pm 13$ years), mainly women (67.5\%), Caucasian $(96.3 \%)$, and French-speaking $(90.5 \%)$. The majority reported having an elementary school diploma or less $(27.3 \%)$ or a high-school diploma $(35.2 \%)$ as their highest level of education. Differences were observed between the subcohorts of patients defined by BPI tertile scores; those reporting more severe pain disability were younger, reported lower familial income, and were more likely to be on permanent or temporary disability.

\section{Clinical and psychological characteristics}

As reported in Table 2, on average, individuals suffered from pain for 12 years ( \pm 11 years). The proportion of patients reporting a pain duration of 4 years or more tended to be 


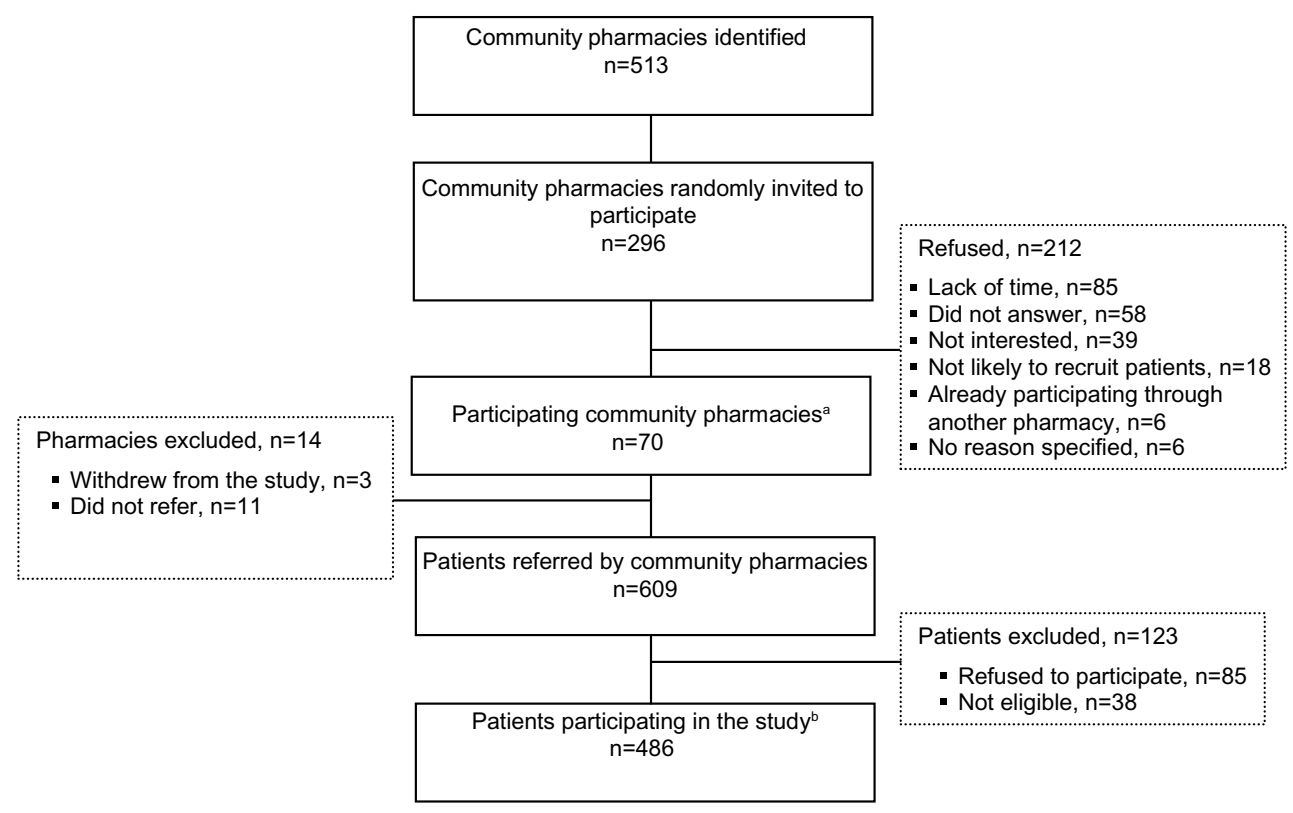

Figure I Recruitment of pharmacies and patients.

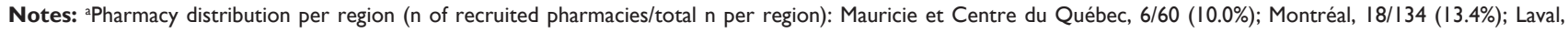
I3/70 (I8.6\%); Lanaudière, 8/77 (I0.4\%); Laurentides, I4/95 (I4.7\%); Montérégie, II/77 (I4.3\%); b patient distribution per region (n of recruited patients per region/total n of patients): Mauricie et Centre du Québec, 44/486 (9.1\%); Montréal, 92/486 (I8.9\%); Laval, $67 / 486$ (I3.8\%); Lanaudière, 9|/486 (I8.7\%); Laurentides, II7/486 (24.1\%); Montérégie, $75 / 186$ (15.4\%).

Abbreviation: $\mathrm{n}$, number.

higher among those with more severe pain disability. In terms of pain frequency, the majority $(75.2 \%)$ were suffering continuously. Patients reported a mean pain intensity score of $6.5( \pm 1.9)$ in the past week. Based on the Hospital Anxiety and Depression $\mathrm{Scale}^{46}, 24.0 \%$ and $40.0 \%$ of participants probably suffered from depression and anxiety, respectively. The mean number of reported pain diagnoses per individual was $2.5( \pm 1.3)$, the most frequent being chronic back pain (64.0\%) and degenerative osteopathies such as osteoarthritis and arthrosis (60.7\%). Patients classified in the severe disability category reported more frequent and more intense pain than those in the mild and moderate categories. They were also more likely to feel depressed and anxious, experience more pain-related sleep problems, and suffer from multiple pain syndromes.

\section{Health care resource utilization and productivity losses}

Individuals were hospitalized for an average of 1.9 (9.9) days annually, where 1.1 (8.3) days were possibly related to CNCP (Table 3). Overall, 19.7\% of the cohort of patients were hospitalized (all causes considered) and 8.9\% of the cohort of patients were hospitalized for a cause that was possibly related to pain (data not reported in table). During this 1-year period, participants visited the ER 0.9 times $( \pm 1.6)$ on average and saw primary care physicians and specialists for an average of $4.8( \pm 4.9)$ times and $2.1( \pm 3.1)$ times, respectively. Patients reporting more pain disability were more likely to have visited the ER or be seen by primary care physicians and specialists. The majority of participants (56.1\%) reported at least one visit to a health care professional other than a physician (data not reported in table), with an annual number of visits per patient averaging 74.6 ( \pm 135.5$)$. Physiotherapists and massage therapists were the most frequently seen with an average of $40.3( \pm 90.1)$ visits per patient and $13.5( \pm 48.8)$ visits per patient, respectively. In terms of pain medication, individuals took an average of $3.9( \pm 2.0)$ and $1.5( \pm 1.6)$ different prescribed and over-the-counter medications to treat pain and/or the adverse effects of pain treatments, respectively. The number of prescribed medications was the highest among patients classified in the severe pain disability subgroup. Patients with more pain disability were more likely to have opioid analgesics dispensed in the year prior to recruitment: mild, 49\%; moderate, 68\%; and severe, $80 \% ; P=0.0001$. Among those on opioids, 19 patients were dispensed a high oral morphine-equivalent dose $(>200 \mathrm{mg}$ per day). These patients were equally distributed across the pain disability subgroups (data not reported in table).

Work productivity data revealed that individuals lost an equivalent of $69.4( \pm 111.3)$ workdays annually due to pain or its treatment; the number of days lost due to absenteeism and presenteeism averaged $57.3( \pm 106.3)$ days and $12.1( \pm 36.0)$ 
Table I Sociodemographic characteristics

\begin{tabular}{|c|c|c|c|c|c|}
\hline & \multirow{2}{*}{$\begin{array}{l}\text { All patients } \\
(n=483)\end{array}$} & \multicolumn{3}{|c|}{ Patients stratified by level of pain disability } & \multirow[t]{2}{*}{$P$-values } \\
\hline & & $\begin{array}{l}\text { Mild disabilitya } \\
(n=165)\end{array}$ & $\begin{array}{l}\text { Moderate disability } \\
(n=\mid 60)\end{array}$ & $\begin{array}{l}\text { Severe disability } \\
(n=\mid 58)\end{array}$ & \\
\hline Age (years), mean (SD) & $59(13)$ & $61(13)$ & $58(12)$ & $57(\mathrm{II})$ & 0.002 \\
\hline Women, n (\%) & $326(67.5)$ & $110(66.7)$ & $106(66.3)$ & $110(69.6)$ & 0.783 \\
\hline Type of insurances, $n$ (\%) & & & & & 0.321 \\
\hline Public (RAMQ) & $295(6 \mathrm{I} . \mathrm{I})$ & $96(58.2)$ & $95(59.4)$ & $104(65.8)$ & \\
\hline Private & $188(38.9)$ & $69(4 \mid .8)$ & $65(40.6)$ & $54(34.2)$ & \\
\hline Ethnicity (Caucasian), ${ }^{\mathrm{d}} \mathrm{n}(\%)$ & $465(96.3)$ & $161(97.6)$ & $154(96.3)$ & $150(94.9)^{e}$ & 0.457 \\
\hline First language (French), ${ }^{f} \mathrm{n}(\%)$ & $437(90.5)$ & $15 \mid(9 \mid .5)$ & $146(91.3)$ & $140(88.6)$ & 0.931 \\
\hline \multicolumn{6}{|l|}{ completed,, $\mathrm{n}(\%)$} \\
\hline None or elementary school & $132(27.3)$ & $48(29.1)$ & $4 \mathrm{I}(25.6)$ & $43(27.2)$ & \\
\hline High-school & $170(35.2)$ & $54(32.7)$ & $61(38.1)$ & $55(34.8)$ & \\
\hline College-technical school or CEGEP & $90(18.6)$ & $26(15.8)$ & $30(18.8)$ & $34(21.5)$ & \\
\hline University & $87(18.0)$ & $36(21.8)$ & $28(17.5)$ & $23(14.6)$ & \\
\hline Civil status, ${ }^{\mathrm{h}} \mathrm{n}(\%)$ & & & & & 0.034 \\
\hline Married or common law & $263(54.5)$ & $98(59.4)$ & $91(56.9)$ & $74(46.8)$ & \\
\hline Single & $64(13.3)$ & $15(9.1)$ & $19(11.9)$ & $30(19.0)$ & \\
\hline Separated/divorced & $98(20.3)$ & $27(16.4)$ & $33(20.6)$ & $38(24.1)$ & \\
\hline Widowed & $57(\mathrm{II} .8)$ & $25(15.2)$ & $16(10.0)$ & $16(10.1)$ & \\
\hline Annual family income, $\mathrm{n}(\%)$ & & & & & 0.011 \\
\hline$<\$ 20,000$ & $128(26.5)$ & $33(20.0)$ & $36(22.5)$ & $59(37.3)$ & \\
\hline$\$ 20,000-\$ 50,000$ & $188(38.9)$ & $66(40.0)$ & $66(4 \mid .3)$ & $56(35.4)$ & \\
\hline$>\$ 50,000$ & $117(24.2)$ & $44(26.7)$ & $42(26.3)$ & $31(19.6)$ & \\
\hline Current work status, ${ }^{\mathrm{j}, \mathrm{k}} \mathrm{n}(\%)$ & & & & & $<0.0001$ \\
\hline Full-time job & $93(19.3)$ & $43(26.1)$ & $33(20.6)$ & $17(10.8)$ & \\
\hline Part-time job & $22(4.6)$ & $9(5.5)$ & $9(5.6)$ & $4(2.5)$ & \\
\hline Temporary disability & $19(3.9)$ & $2(1.2)$ & $7(4.4)$ & $10(6.3)$ & \\
\hline Permanent disability & $86(17.8)$ & $16(9.7)$ & $24(15.0)$ & $46(29.1)$ & \\
\hline
\end{tabular}

Notes: aPatients in the first BPI tertile (scores ranging from 0-4.3); ${ }^{b}$ patients in the second BPI tertile (scores ranging from 4.3I-6.4); ${ }^{\mathrm{p}} \mathrm{patients}$ in the third BPI tertile (scores ranging from 6.4I-10.0); ${ }^{d}$ additional categories were reported: Black; Native American; Hispanic; Asian; and other; 'one patient refused to answer; fadditional categories were reported: English; Spanish; Italian; Portuguese; German; Arabic; Chinese; Japanese; and Vietnamese; :one and three patients refused to answer in the mild and severe disability groups, respectively; 'one patient refused to answer in the moderate disability group; 'twenty-two, 16 , and 12 patients refused to answer in the mild, moderate, and severe disability groups, respectively; 'additional categories were reported: homemaker; student; unemployed; laid off; and volunteer; 'two, seven, and four patients refused to answer in the mild, moderate, and severe disability groups, respectively.

Abbreviations: n, number; SD, standard deviation; RAMQ, Régie de l'assurance maladie du Québec; CEGEP, Collège d'enseignement général et professionnel; BPI, Brief Pain Inventory.

days, respectively. Annual workdays lost were higher in individuals with more severe pain disability.

\section{Unadjusted direct health care and productivity costs}

The mean annual total direct health care costs per patient averaged CAD $\$ 7,334( \pm \$ 9,276), \operatorname{CAD} \$ 11,128( \pm \$ 19,131)$, and $\mathrm{CAD} \$ 10,311( \pm \$ 11,501)$ for patients with mild, moderate, and severe pain disability, respectively (Table 4). Major cost components included nonpharmacologic health care services, which accounted for 47.1\% (CAD \$4,505/CAD $\$ 9,565)$ of the total direct health care costs, hospitalizations and ER visits (24.6\%), prescribed medications (20.5\%), and outpatient medical visits $(6.3 \%)$. For patients with mild, moderate, and severe pain disability, productivity costs per patient averaged CAD $\$ 4,523( \pm \$ 8,951), \mathrm{CAD} \$ 8,254$
$( \pm \$ 13,386)$, and CAD $\$ 8,536( \pm \$ 12,077)$, respectively. Absenteeism and presenteeism costs accounted for $71.4 \%$ and $28.6 \%$ of those costs, respectively. When combining the direct health care costs and productivity costs, the mean annual costs per patient were equal to CAD $\$ 11,857$ $( \pm \$ 13,685), \mathrm{CAD} \$ 19,382( \pm \$ 23,228)$, and $\mathrm{CAD} \$ 18,847$ $( \pm \$ 18,734)$ for patients with mild, moderate, and severe pain disability, respectively. The costs of hospitalizations, outpatient visits, prescribed medications, and total costs were found to be significantly and positively related to the level of pain disability.

\section{Adjusted direct health care costs and productivity costs}

Once they were adjusted for age, sex, pain duration, and Charlson comorbidity scores, the mean annual direct costs 
Table 2 Clinical and psychosocial characteristics

\begin{tabular}{|c|c|c|c|c|c|}
\hline & \multirow{2}{*}{$\begin{array}{l}\text { All patients } \\
(n=483)\end{array}$} & \multicolumn{3}{|c|}{ Patients stratified by level of pain disability } & \multirow[t]{2}{*}{$P$-values } \\
\hline & & $\begin{array}{l}\text { Mild disability } \\
(\mathrm{n}=165)\end{array}$ & $\begin{array}{l}\text { Moderate disability } \\
(n=160)\end{array}$ & $\begin{array}{l}\text { Severe disabilityc } \\
(n=158)\end{array}$ & \\
\hline Duration of pain (years), mean (SD) & $12(11)$ & II (II) & $I I(I I)^{d}$ & $13(12)$ & 0.186 \\
\hline Duration of pain, $n(\%)^{d}$ & & & & & 0.003 \\
\hline $6-12$ months & $37(7.7)$ & $17(10.3)$ & $12(7.5)$ & $8(5.1)$ & \\
\hline 13-14 months & I $(0.2)$ & I (0.6) & $0(0.0)$ & $0(0.0)$ & \\
\hline I5-36 months & $74(15.3)$ & $35(21.2)$ & $23(14.4)$ & $16(10.1)$ & \\
\hline $37-48$ months & $32(6.6)$ & $6(3.6)$ & $12(7.5)$ & $14(8.9)$ & \\
\hline 49 months or more & $338(70.0)$ & $106(64.2)$ & $112(70.0)$ & $120(75.9)$ & \\
\hline Frequency of pain in the past 7 days, $n(\%)$ & & & & & 0.000 \\
\hline Always & $363(75.2)$ & $99(60.0)$ & $125(78.1)$ & $139(88.0)$ & \\
\hline Occasionally & $116(24.0)$ & $62(37.6)$ & $35(21.9)$ & $19(12.0)$ & \\
\hline Never & $4(0.8)$ & $4(2.4)$ & $0(0.0)$ & $0(0.0)$ & \\
\hline $\begin{array}{l}\text { Average pain intensity in the past } 7 \text { days, } \\
\text { mean (SD) }\end{array}$ & $6.5(1.9)$ & $5.5(1.9)^{\mathrm{e}}$ & $6.7(1.6)$ & $7.3(1.6)$ & 0.000 \\
\hline Pain functional impact score, ${ }^{f}$ mean (SD) & $5.3(2.2)$ & $2.8(1.2)$ & $5.5(0.6)$ & $7.7(0.8)$ & 0.000 \\
\hline Depression, ${ }^{8} \mathrm{n}(\%)$ & $116(24.0)$ & $5(3.0)$ & $38(23.8)$ & $73(46.2)^{d}$ & 0.000 \\
\hline Anxiety, ${ }^{g} \mathrm{n}(\%)$ & $193(40.0)$ & $34(20.6)$ & $70(43.8)$ & $89(56.3)^{d}$ & 0.000 \\
\hline Pain sleep impact score, ${ }^{\mathrm{h}}$ mean (SD) & $5.1(2.9)$ & $3.3(2.6)$ & $5.4(2.7)$ & $6.6(2.4)$ & 0.000 \\
\hline Comorbidity index,' mean (SD) & $2.5(1.9)$ & $2.6(2.0)$ & $2.3(1.7)$ & $2.5(1.9)$ & 0.303 \\
\hline $\begin{array}{l}\text { Number of self-reported pain diagnoses } \\
\text { per patient, mean (SD) }\end{array}$ & $2.5(1.3)$ & $2.3(1.2)$ & $2.4(\mathrm{I} .3)$ & $2.9(1.5)$ & 0.000 \\
\hline \multicolumn{6}{|l|}{$\begin{array}{l}\text { per patient, mean (SD) } \\
\text { Self-reported pain diagnoses, n (\%)i }\end{array}$} \\
\hline Chronic back pain & $309(64.0)$ & $90(54.5)$ & $104(65.0)$ & II 5 (72.8) & 0.003 \\
\hline Chronic neck pain & $186(38.5)$ & $52(31.5)$ & $60(37.5)$ & $74(46.8)$ & 0.017 \\
\hline Fibromyalgia & II4 (23.6) & $33(20.0)$ & $33(20.6)$ & $48(30.4)$ & 0.050 \\
\hline $\begin{array}{l}\text { Osteoarthritis, arthrosis, and other } \\
\text { degenerative osteopathies }\end{array}$ & $293(60.7)$ & $102(61.8)$ & $88(55.0)$ & $103(65.2)$ & 0.165 \\
\hline $\begin{array}{l}\text { Rheumatoid arthritis and other } \\
\text { inflammatory osteopathies }\end{array}$ & 55 (II.4) & $17(10.3)$ & $17(10.6)$ & $21(13.3)$ & 0.653 \\
\hline $\begin{array}{l}\text { Tendinitis, bursitis, capsulitis, and } \\
\text { epicondylitis }\end{array}$ & I0I (20.9) & $28(17.0)$ & 35 (21.9) & $38(24.1)$ & 0.275 \\
\hline Visceral pain & $74(15.3)$ & $16(9.7)$ & $22(13.8)$ & $36(22.8)$ & 0.004 \\
\hline Neuropathic pain & $88(18.2)$ & $38(23.0)$ & $26(16.3)$ & $24(15.2)$ & 0.139 \\
\hline
\end{tabular}

Notes: ${ }^{a}$ Patients in the first BPI tertile (scores ranging from 0-4.3); ${ }^{b}$ patients in the second BPI tertile (scores ranging from 4.3I-6.4); ${ }^{p}$ patients in the third BPI tertile (scores ranging from 6.4I-10.0); 'one missing value; 'two missing values; ${ }^{\mathrm{B}} \mathrm{BPI}$ questionnaire; 8 Hospital Anxiety and Depression Scale; presence of depression and anxiety disorder is probable when score $\geq \mathrm{II}$; ${ }^{h}$ Chronic Pain Sleep Inventory questionnaire; 'Charlson Comorbidity Index; individuals could report more than one diagnosis.

Abbreviations: n, number; SD, standard deviation; BPI, Brief Pain Inventory.

per patient averaged CAD \$7,374 (95\% CI: \$5,819-\$8,930), CAD \$10,524 (95\% CI: \$8,383-\$12,665), and CAD \$9,546 (95\% CI: \$7,502-\$11,590) for patients with mild, moderate, and severe pain disability, respectively (Table 5). Productivity costs were CAD \$3,005 (95\% CI: \$1,587-\$4,422), CAD \$5,083 (95\% CI: \$2,647-\$7,519), and CAD \$5,385 (95\% CI: $\$ 2,789-\$ 7,981$ ) for each group, with total costs adding up to CAD \$12,913 (95\% CI: \$10,534-\$15,292), CAD \$17,970 (95\% CI: \$14,782-\$21,159), and CAD \$17,292 (95\% CI: $\$ 14,075-\$ 20,510)$. A significant positive association was observed between the level of pain disability, as well as the total adjusted direct health care costs (considering painrelated hospitalizations only) and productivity costs: mild disability, CAD \$12,118; moderate disability, CAD \$18,278; and severe disability, CAD $\$ 19,216 ; P=0.001$.

\section{Discussion}

This is one of the rare studies providing a comprehensive evaluation of the economic burden of CNCP in a large cohort of patients followed up in primary care. The direct health care costs of CNCP in this cohort of patients represented nearly $60 \%$ of the total direct health care and productivity costs. The use of complementary health care services accounted for almost $50 \%$ of the direct costs. The total direct health care and productivity costs averaged CAD $\$ 16,636$ per patient per year and varied according to the level of pain disability - the more disabled the patients were, the higher the costs were. Although high, these numbers represent only a portion of the true costs since they do not include other indirect costs such as patients' travel expenses, paid household help, expenses incurred by family members, and so on. 
Table 3 Annual health care resource utilization and productivity losses per patient

\begin{tabular}{|c|c|c|c|c|c|}
\hline \multirow[t]{2}{*}{ Mean (SD) } & \multirow{2}{*}{$\begin{array}{l}\text { All patients } \\
(n=483)\end{array}$} & \multicolumn{3}{|c|}{ Patients stratified by level of pain disability } & \multirow[t]{2}{*}{ P-value } \\
\hline & & $\begin{array}{l}\text { Mild disability } \\
(\mathrm{n}=165)\end{array}$ & $\begin{array}{l}\text { Moderate disability } \\
(n=160)\end{array}$ & $\begin{array}{l}\text { Severe disabilityc } \\
(n=158)\end{array}$ & \\
\hline \multicolumn{6}{|c|}{ Health care resources utilization per patient } \\
\hline \multicolumn{6}{|c|}{ Number of hospitalization days } \\
\hline All causes & $1.9(9.9)$ & I.I (5.8) & $3.2(15.1)$ & $1.5(5.5)$ & 0.146 \\
\hline Pain-related as possible cause & I.I (8.3) & $0.7(5.6)$ & $1.8(12.6)$ & $0.8(4.2)$ & 0.468 \\
\hline \multicolumn{6}{|l|}{ Number of physician visits } \\
\hline Primary care & $0.4(2.7)$ & $0.2(1.3)$ & $0.4(2.3)$ & $0.6(3.9)$ & 0.423 \\
\hline Specialists & I.I (4.4) & $0.8(3.8)$ & $1.4(5.5)$ & I.I (3.7) & 0.449 \\
\hline Number of emergency room visits & $0.9(1.6)$ & $0.6(1.3)$ & $0.9(1.8)$ & I.I (I.7) & 0.046 \\
\hline \multicolumn{6}{|l|}{ Number of physician visits at emergency } \\
\hline Primary care & $0.2(1.3)$ & $0.2(1.3)$ & $0.2(1.3)$ & $0.3(1.2)$ & 0.645 \\
\hline Specialists & $0.9(3.3)$ & $0.4(1.9)$ & $1.2(4.0)$ & I.I (3.7) & 0.085 \\
\hline \multicolumn{6}{|l|}{ Number of outpatient physician visits } \\
\hline Primary care & $4.8(4.9)$ & $4.4(3.9)$ & $4.1(4.1)$ & $6.0(6.3)$ & 0.001 \\
\hline Specialists & $2.1(3.1)$ & $1.9(2.7)$ & $1.8(2.7)$ & $2.8(3.8)$ & 0.008 \\
\hline \multicolumn{6}{|l|}{ Number of outpatient tests and interventions } \\
\hline All & $10.7(7.5)$ & $10.0(6.9)$ & $10.6(8.1)$ & II.6 (7.3) & 0.136 \\
\hline Pain-related & $1.4(1.8)$ & $1.2(1.6)$ & $1.5(1.9)$ & $1.4(1.8)$ & 0.322 \\
\hline \multicolumn{6}{|l|}{$\begin{array}{l}\text { Number of complementary health care } \\
\text { provider visits }\end{array}$} \\
\hline Psychotherapists & $2.7(13.4)$ & $\mathrm{I} .7(9.5)$ & $2.9(14.7)$ & $3.5(15.4)$ & 0.451 \\
\hline Physiotherapists & $40.3(90.1)$ & $31.3(75.5)$ & $45.3(98.0)$ & $44.6(95.6)$ & 0.291 \\
\hline Massage therapists & $13.5(48.8)$ & $9.0(34.3)$ & $15.1(49.6)$ & $16.5(59.6)$ & 0.336 \\
\hline Occupational therapists & $5.4(30.7)$ & $4.4(30.6)$ & $6.4(29.4)$ & $5.4(32.3)$ & 0.848 \\
\hline Acupuncturists & $4.3(21.3)$ & 4.7 (19.9) & $4.2(18.6)$ & $4.0(25.1)$ & 0.946 \\
\hline Osteopaths & $4.2(18.0)$ & $6.4(22.8)$ & $3.6(16.8)$ & $2.7(12.8)$ & 0.159 \\
\hline Chiropractors & $4.2(18.9)$ & $6.3(23.8)$ & $2.3(12.4)$ & $3.9(18.5)$ & 0.157 \\
\hline Total & $74.6(135.5)$ & $63.9(110.8)$ & $79.7(142.7)$ & $80.7(150.8)$ & 0.454 \\
\hline $\begin{array}{l}\text { Number of prescribed pain-related } \\
\text { medications }^{d}\end{array}$ & $3.9(2.0)$ & $3.4(1.9)$ & $4.1(2.0)$ & $4.2(2.0)$ & 0.000 \\
\hline $\begin{array}{l}\text { Number of over-the-counter pain-related } \\
\text { medications }^{d}\end{array}$ & $1.5(1.6)$ & $1.5(1.6)$ & $1.5(1.7)$ & $1.5(1.6)$ & 0.897 \\
\hline \multicolumn{6}{|l|}{ Annual productivity losses per patient } \\
\hline Number of absenteeism days ${ }^{e}$ & $57.3(106.3)$ & $32.9(83.4)$ & $54.9(104.7)$ & $85.3(122.0)$ & 0.000 \\
\hline Number of presenteeism days ${ }^{f}$ & $12.1(36.0)$ & $8.7(24.1)$ & $19.0(46.7)$ & $8.7(33.0)$ & 0.012 \\
\hline Total number of workdays lost & $69.4(111.3)$ & $41.6(86.3)$ & $73.9(\mid 14.5)$ & $94.0(124.7)$ & 0.000 \\
\hline
\end{tabular}

Complementary health care services (for example, physiotherapy, massage therapy, occupational therapy) are known to be extensively used by individuals with $\mathrm{CNCP}^{7,53}$ including those with chronic low back pain. ${ }^{54}$ Not considering these costs may, therefore, lead to an important underestimation of the direct health care costs of CNCP and may explain discrepancies among studies. For example, Lachaine et $\mathrm{al}^{12}$ estimated that the annual direct health care costs associated with neuropathic painful disorders in Quebec (Canada) averaged CAD $\$ 4,065$ per patient ( $\pm \$ 6,798$ [2007 values]; $\$ 4,339$ [2011 values]). In another study on the costs associated with fibromyalgia in Quebec, ${ }^{11}$ the direct health care costs added up to CAD $\$ 4,163$ ( $\pm \$ 7,536$ [2002 values]; $\$ 4,960$ [2011 values]). Differences with our results might be explained by the fact that complementary health care services were not considered in these studies.

In patients with chronic pain, higher than normal absenteeism rates, ${ }^{2}$ as well as significant interference with work performance, ${ }^{8}$ have been reported. In our study, the mean annual cost associated with productivity losses represented about $40 \%$ of the total direct health care and productivity costs. This proportion is consistent with earlier observations made in individuals suffering from fibromyalgia syndrome ${ }^{55}$ and chronic low back pain ${ }^{54}$ where the proportion of costs associated with productivity 
Table 4 Crude annual direct health care costs and productivity costs (CAD dollars) per patient

\begin{tabular}{|c|c|c|c|c|c|}
\hline \multirow[t]{2}{*}{ Mean (SD) } & \multirow{2}{*}{$\begin{array}{l}\text { All patients } \\
(n=483)\end{array}$} & \multicolumn{3}{|c|}{ Patients stratified by level of pain disability } & \multirow[t]{2}{*}{$P$-values } \\
\hline & & $\begin{array}{l}\text { Mild disability } \\
(n=165)\end{array}$ & $\begin{array}{l}\text { Moderate disability } \\
(n=160)\end{array}$ & $\begin{array}{l}\text { Severe disability } \\
(n=158)\end{array}$ & \\
\hline \multicolumn{6}{|l|}{ Direct health care costs } \\
\hline \multicolumn{6}{|l|}{ Hospitalizations } \\
\hline All hospitalization costs, except physician visits & I,908 $(9,877)$ & I, I 48 (5,849) & $3,117(15,080)$ & $\mathrm{I}, 480(5,583)$ & 0.021 \\
\hline Pain-related hospitalization costs & $\mathrm{I}, 102(8,304)$ & $739(5,555)$ & $1,763(12,610)$ & $810(4,213)$ & 0.043 \\
\hline General practitioner visits & $14(98)$ & $9(47)$ & $13(9 \mid)$ & $22(137)$ & 0.004 \\
\hline Specialist visits & $114(321)$ & $106(307)$ & $138(380)$ & $99(267)$ & 0.508 \\
\hline Total costs & $2,036(10,137)$ & $1,262(6,053)$ & $3,266(15,404)$ & $\mathrm{I}, 600(5,878)$ & 0.030 \\
\hline \multicolumn{6}{|l|}{ Emergency room visits } \\
\hline Emergency room costs & $250(48 I)$ & $179(369)$ & $267(553)$ & $308(498)$ & 0.150 \\
\hline General practitioner visits & $8(44)$ & $5(33)$ & $6(42)$ & $13(55)$ & 0.001 \\
\hline Specialist visits & $62(289)$ & $43(260)$ & $65(262)$ & $78(34 I)$ & 0.455 \\
\hline Total costs & $320(686)$ & $227(528)$ & $338(753)$ & $399(752)$ & 0.148 \\
\hline \multicolumn{6}{|l|}{ Outpatient medical consultations } \\
\hline Primary care visits & $231(247)$ & $211(205)$ & $204(233)$ & $278(291)$ & 0.129 \\
\hline Specialist visits & $163(240)$ & 137 (195) & 144 (222) & $209(290)$ & 0.094 \\
\hline All outpatient tests and interventions & $145(170)$ & $132(163)$ & $149(186)$ & $152(161)$ & 0.699 \\
\hline Pain-related tests and interventions & $66(102)$ & $50(80)$ & $75(116)$ & $72(105)$ & 0.115 \\
\hline Total costs & $604(54 I)$ & $531(437)$ & $573(561)$ & $712(602)$ & 0.048 \\
\hline \multicolumn{6}{|l|}{ Complementary health care provider visits } \\
\hline Psychotherapists & $257(1,276)$ & $160(902)$ & $279(1,400)$ & $335(1,466)$ & 0.103 \\
\hline Physiotherapists & $2,337(5,231)$ & $\mathrm{I}, 8 \mathrm{I} 8(4,382)$ & $2,626(5,688)$ & $2,586(5,546)$ & 0.528 \\
\hline Massage therapists & $78 \mid(2,830)$ & $521(1,992)$ & $873(2,876)$ & $959(3,457)$ & 0.181 \\
\hline Occupational therapists & $343(1,944)$ & $281(1,937)$ & $405(1,86 I)$ & $345(2,043)$ & 0.607 \\
\hline Acupuncturists & $249(1,235)$ & $274(1,153)$ & $243(1,077)$ & $230(1,455)$ & 0.875 \\
\hline Osteopaths & $339(1,426)$ & $507(I, 80 I)$ & $288(1,326)$ & $216(1,011)$ & 0.043 \\
\hline Chiropractors & $198(899)$ & $299(1,131)$ & $108(587)$ & $185(880)$ & 0.013 \\
\hline Total costs & $4,505(8,115)$ & $3,860(6,706)$ & $4,822(8,599)$ & $4,856(8,924)$ & 0.640 \\
\hline $\begin{array}{l}\text { Prescribed analgesics and medication to treat side } \\
\text { effects of medication }\end{array}$ & $\mathrm{I}, 963(2,978)$ & $\mathrm{I}, 304(\mathrm{I}, 728)$ & I,979 $(3,029)$ & $2,635(3,728)$ & $<0.001$ \\
\hline $\begin{array}{l}\text { Over-the-counter analgesics and medication to } \\
\text { treat side effects }\end{array}$ & $136(60 \mid)$ & 150 (709) & I50 (708) & $108(275)$ & 0.341 \\
\hline Total direct health care costs & $9,565(13,993)$ & $7,334(9,276)$ & $1 \mathrm{I}, 128(19,13 \mathrm{I})$ & $|0,3| I(|I, 50|)$ & 0.008 \\
\hline \multicolumn{6}{|l|}{ Productivity costs } \\
\hline Absenteeism & $5,052(9,429)$ & $3,068(7,677)$ & $5,084(9,743)$ & $7,091(10,339)$ & 0.082 \\
\hline Presenteeism & $2,020(6,013)$ & $\mathrm{I}, 455(4,027)$ & $3,|7|(7,804)$ & $\mathrm{I}, 445(5,5 \mathrm{I} \mathrm{I})$ & 0.057 \\
\hline Total productivity costs & $7,072(11,716)$ & $4,523(8,95 I)$ & $8,254(13,386)$ & $8,536(12,077)$ & 0.158 \\
\hline Total overall costs & $16,636(19,182)$ & $11,857(13,685)$ & $19,382(23,228)$ & $18,847(18,734)$ & $<0.001$ \\
\hline
\end{tabular}

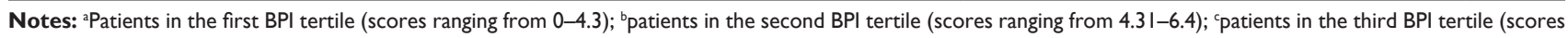
ranging from $6.4 \mathrm{I}-10.0)$.

Abbreviations: CAD, Canadian; SD, standard deviation; n, number; BPI, Brief Pain Inventory.

losses accounted for more than half of the total costs. Similar observations were also made by Guerriere et $\mathrm{al}^{24}$ in a population of chronic pain patients waiting for treatment in tertiary care pain clinics. Although they remain insufficiently documented, presenteeism costs should be systematically taken into consideration, as illustrated by an Australian and an American study where these costs accounted for the majority of the CNCP costs..$^{14,21}$

When combined, the direct health care costs and productivity costs led to mean annual total costs of CAD $\$ 16,636$ per patient, which compares with previous estimates in fibromyalgia (US \$15,000 [2009 values]; CAD \$15,489 [2011 values]), ${ }^{56}$ chronic low back pain (US $\$ 19,473$
[2002 values]; CAD \$23,566 [2011 values]), ,4 and osteoarthritis (US \$16,146 [2005 values]; CAD \$18,189 [2011 values]). ${ }^{57}$ Other studies have also reported that economic burden increases with the severity of pain disability. For example, among individuals with rheumatoid arthritis, increases in self-report disability status, as measured by the Health Assessment Questionnaire, were associated with higher costs. ${ }^{17,18,58,59}$ Costs incurred by chronic low back pain and by neuropathic pain were also found to vary as a function of the degree of disability levels. ${ }^{54,60}$ However, the present study is the first to demonstrate this association for a variety of chronic pain diagnoses in a primary care setting. 
Table 5 Adjusted annual direct health care costs and productivity costs (CAD dollars) per patient

\begin{tabular}{|c|c|c|c|c|}
\hline Mean $(95 \% \mathrm{Cl})$ & $\begin{array}{l}\text { Mild disability }{ }^{a} \\
(n=165)\end{array}$ & $\begin{array}{l}\text { Moderate disability } \\
(n=160)\end{array}$ & $\begin{array}{l}\text { Severe disability } \\
(n=158)\end{array}$ & $P$-value \\
\hline \multicolumn{5}{|l|}{ Direct health care costs } \\
\hline \multicolumn{5}{|l|}{ Hospitalization } \\
\hline All-cause hospitalizations & $897(4 \mid 5 ; 1,380)$ & $2,857(I, 348 ; 4,365)$ & $2,021(849 ; 3,193)$ & 0.012 \\
\hline Pain-related hospitalizations & $326(146 ; 507)$ & $\mathrm{I}, 700(707 ; 2,693)$ & $883(224 ; 1,542)$ & 0.001 \\
\hline Emergency room visits & $228(137 ; 319)$ & $339(202 ; 476)$ & $400(238 ; 563)$ & 0.149 \\
\hline Outpatient consultation visits & $532(44 I ; 622)$ & $574(475 ; 673)$ & $713(589 ; 837)$ & 0.048 \\
\hline Complementary health care provider visits & $4,165(2,553 ; 5,776)$ & $4,279(2,638 ; 5,921)$ & $4,345(2,665 ; 6,024)$ & 0.989 \\
\hline Prescribed analgesics & $1,428(I, \mid 43 ; 1,713)$ & $1,976(1,589 ; 2,363)$ & $2,330(I, 848 ; 2,812)$ & 0.004 \\
\hline Over-the-counter analgesics & $112(74 ; 150)$ & I $38(9|;| 85)$ & $116(76 ; 155)$ & 0.646 \\
\hline Total & $7,374(5,819 ; 8,930)$ & $10,524(8,383 ; 12,665)$ & $9,546(7,502 ; 11,590)$ & 0.051 \\
\hline \multicolumn{5}{|l|}{ Productivity costs } \\
\hline Absenteeism & $2,320(I, I 79 ; 3,460)$ & $3,175(1,587 ; 4,763)$ & $4,922(2,449 ; 7,395)$ & 0.108 \\
\hline Presenteeism & $826(368 ; 1,284)$ & $\mathrm{I}, 76 \mathrm{I}(84 \mathrm{I} ; 2,68 \mathrm{I})$ & $300(130 ; 469)$ & 0.000 \\
\hline Total & $3,005(1,587 ; 4,422)$ & $5,083(2,647 ; 7,519)$ & $5,385(2,789 ; 7,981)$ & 0.194 \\
\hline \multicolumn{5}{|c|}{ Total direct health care and productivity costs } \\
\hline Including all cause hospitalizations & $12,9 \mid 3(10,534 ; \mid 15,292)$ & $17,970(\mid 4,782 ; 21,159)$ & $17,292(\mid 4,075 ; 20,510)$ & 0.024 \\
\hline Including pain-related hospitalizations & |2, I I8 (9,844; |4,393) & I8,278 (I4,909; 2I,648) & $19,216(15,538 ; 22,894)$ & 0.001 \\
\hline
\end{tabular}

Notes: aPatients in the first BPI tertile (scores ranging from 0-4.3); ${ }^{b}$ patients in the second BPI tertile (scores ranging from 4.3I-6.4); ${ }^{\mathrm{p}} \mathrm{patients}$ in the third BPI tertile (scores ranging from $6.4 \mathrm{I}-10.0$ ).

Abbreviations: CAD, Canadian; $\mathrm{Cl}$, confidence interval; n, number; BPI, Brief Pain Inventory.

\section{Strengths and limitations}

Like any other study, the present one has some limitations that must be taken into consideration. Patients were recruited only if they had an active analgesic prescription from a primary care physician in their pharmacy chart. Our results cannot be extrapolated to those having no active analgesic prescriptions or only prescriptions from a specialist. Furthermore, some of our results are based on patient self-reports and may be influenced by social desirability (tendency to answer questions in a manner that will be viewed favorably by others) and memory biases. However, the research assistants who conducted the telephone interviews were well trained and used a structured interview protocol. Self-administered questionnaires were used to document more sensitive information such as levels of depression and anxiety. Some assumptions were also made to estimate the annual costs. Annual productivity costs, as well as annual use of over-the-counter medication and complementary health care services, were estimated using data covering a 6-month period. This may have resulted in an overestimation or underestimation of costs, as resource utilization rates may have changed over time. Furthermore, the frequency of use was not precisely documented. Finally, we took into account the direct costs to patients associated with different self-management techniques (eg cost of physiotherapy). However, we did not consider the impact this may have on caregiver time (eg time absent from work for the patient's wife).

Despite those limitations, this study offers a comprehensive description of the direct health care costs and productivity costs associated with CNCP. The use of administrative databases and pharmacy charts enabled the precise documentation of prescribed pharmacological treatments of participants, as well as their use of health care resources. Furthermore, we also assessed the use of over-the-counter medication and complementary health care services, both documented through telephone interviews with the patients. The structured interview protocol also allowed for the documentation of productivity losses due to pain or its treatment, which were further translated into productivity costs based on the method previously described by $\mathrm{Hu}$ et al. ${ }^{42}$

\section{Conclusion}

CNCP among primary care patients is associated with substantial economic burden not only for the health care system and the workforce, but also for patients themselves. These costs tend to increase as pain causes more limitations in a patient's daily activities. Further research is clearly needed to improve the management of CNCP in primary care. Finding efficient strategies to reduce further chronicity of pain problems is certainly an avenue that needs to be explored, as it could alleviate not only the burden of illness, but also its associated costs.

\section{Acknowledgments}

We are grateful for the excellent collaboration of community pharmacists and patients who took part in this project. This work was conducted as part of the master research project of Alexandra Beaulieu-Boivin. We acknowledge her time and effort in the conduct of this analysis. Special thanks to Chantal Legris for the preparation and submission of this 
article. Lyne Lalonde and Sylvie Perreault are scientists supported by the Fonds de recherche du Québec - Santé.

\section{Disclosure}

This study was funded by a team grant - Community Alliances for Health Research and Knowledge Exchange in Pain of the Canadian Institutes of Health Research (CIHR) in partnership with AstraZeneca Canada Inc. (Grant \# 86787), and by Pfizer Canada Inc. The authors report no other conflicts of interest in this work.

\section{References}

1. Classification of chronic pain. Descriptions of chronic pain syndromes and definitions of pain terms. Prepared by the International Association for the Study of Pain, Subcommittee on Taxonomy. Pain Suppl. 1986;3:S1-S226.

2. Moulin DE, Clark AJ, Speechley M, Morley-Forster PK. Chronic pain in Canada - prevalence, treatment, impact and the role of opioid analgesia. Pain Res Manag. 2002;7(4):179-184.

3. Boulanger A, Clark AJ, Squire P, Cui E, Horbay GL. Chronic pain in Canada: have we improved our management of chronic noncancer pain? Pain Res Manag. 2007;12(1):39-47.

4. Millar WJ. Chronic pain. Health Rep. 1996;7(4):47-53, 51-58.

5. Ospina M, Harstall C. Prevalence of Chronic Pain: An Overview. Edmonton, AB: Alberta Heritage Foundation for Medical Research; 2002. Available from: http://ihe.ca/documents/prevalence_chronic_ pain_0.pdf. Accessed April 6, 2011.

6. Kerr S, Fairbrother G, Crawford M, Hogg M, Fairbrother D, Khor KE. Patient characteristics and quality of life among a sample of Australian chronic pain clinic attendees. Intern Med J. 2004;34(7):403-409.

7. Breivik H, Collett B, Ventafridda V, Cohen R, Gallacher D. Survey of chronic pain in Europe: prevalence, impact on daily life, and treatment. Eur J Pain. 2006;10(4):287-333.

8. Gureje O, Von Korff M, Simon GE, Gater R. Persistent pain and well-being: a World Health Organization Study in Primary Care. JAMA. 1998;280(2):147-151.

9. McWilliams LA, Cox BJ, Enns MW. Mood and anxiety disorders associated with chronic pain: an examination in a nationally representative sample. Pain. 2003;106(1-2):127-133.

10. Fautrel B, Clarke AE, Guillemin F, et al. Costs of rheumatoid arthritis: new estimates from the human capital method and comparison to the willingness-to-pay method. Med Decis Making. 2007;27(2):138-150.

11. Lachaine J, Beauchemin C, Landry PA. Clinical and economic characteristics of patients with fibromyalgia syndrome. Clin J Pain. 2010;26(4):284-290.

12. Lachaine J, Gordon A, Choinière M, Collet JP, Dion D, Tarride JE. Painful neuropathic disorders: an analysis of the Régie de 1'Assurance Maladie du Québec database. Pain Res Manag. 2007;12(1):31-37.

13. Agence d'évaluation des technologies et des modes d'intervention en santé. Management of Chronic (Non-Cancer) Pain: Organization of Health Services. Montreal, QC: Agence d'évaluation des technologies et des modes d'intervention en santé; 2006

14. van Leeuwen MT, Blyth FM, March LM, Nicholas MK, Cousins MJ. Chronic pain and reduced work effectiveness: the hidden cost to Australian employers. Eur J Pain. 2006;10(2):161-166.

15. Kumpusalo E, Mäntyselkä P, Takala J. Chronic pain in primary care. Fam Pract. 2000;17(4):352.

16. Pizzi LT, Carter CT, Howell JB, Vallow SM, Crawford AG, Frank ED. Work loss, healthcare utilization, and costs among US employees with chronic pain. Disease Management and Health Outcomes. 2005;13(3):201-208.
17. Michaud K, Messer J, Choi HK, Wolfe F. Direct medical costs and their predictors in patients with rheumatoid arthritis: a three-year study of 7,527 patients. Arthritis Rheum. 2003;48(10):2750-2762.

18. Yelin E, Wanke LA. An assessment of the annual and long-term direct costs of rheumatoid arthritis: the impact of poor function and functional decline. Arthritis Rheum. 1999;42(6):1209-1218.

19. Clarke AE, Zowall H, Levinton C, et al. Direct and indirect medical costs incurred by Canadian patients with rheumatoid arthritis: a 12 year study. J Rheumatol. 1997;24(6):1051-1060.

20. Burton W, Morrison A, Maclean R, Ruderman E. Systematic review of studies of productivity loss due to rheumatoid arthritis. Occup Med (Lond). 2006;56(1):18-27.

21. Gaskin DJ, Richard P. The economic costs of pain in the United States. J Pain. 2012;13(8):715-724.

22. Maetzel A, Li LC, Pencharz J, Tomlinson G, Bombardier C; Community Hypertension and Arthritis Project Study Team. The economic burden associated with osteoarthritis, rheumatoid arthritis, and hypertension: a comparative study. Ann Rheum Dis. 2004;63(4): 395-401.

23. Penrod JR, Bernatsky S, Adam V, Baron M, Dayan N, Dobkin PL. Health services costs and their determinants in women with fibromyalgia. J Rheumatol. 2004;31(7):1391-1398.

24. Guerriere DN, Choinière $M$, Dion D, et al. The Canadian STOPPAIN project - Part 2: What is the cost of pain for patients on waitlists of multidisciplinary pain treatment facilities? Can J Anaesth. 2010;57(6):549-558.

25. Lalonde L [webpage on the Internet]. Optimisation de la gestion de la douleur chronique en soins de première ligne [Optimizing the management of chronic pain in ambulatory primary care]. ACCORD Regroupment des forces pour gérer la douleur chronique; Montreal,QC; 2009. Available from: http://www.programmeaccord.org/volets/premiereligne. Accessed April 22, 2013.

26. Jouini G, Choiniere M, Martin E, Perreault S, Berbiche D, Lussier D et al. Pharmacotherapeutic management of chronic noncancer pain in primary care: lessons for pharmacists. J Pain Res. 2014;7:163-173.

27. Atlas de la santé et des services sociaux du Québec! [webpage on the Internet]. Québec: Santé et Services sociaux Québec; 2014. Available from: http://www.msss.gouv.qc.ca/statistiques/atlas/atlas/index.php. Accessed May 12, 2014.

28. Hoffman DL, Sadosky A, Dukes EM, Alvir J. How do changes in pain severity levels correspond to changes in health status and function in patients with painful diabetic peripheral neuropathy? Pain. 2010;149(2):194-201.

29. World Health Organization. A new understanding of chronic pain. In: Kaplun A, editor. Health Promotion and Chronic Illness. Discovering a New Quality of Health. Copenhagen, Denmark: WHO Regional Publications; 1992;141-226.

30. Jovey RD, Ennis J, Gardner-Nix J, et al; Canadian Pain Society. Use of opioid analgesics for the treatment of chronic noncancer pain a consensus statement and guidelines from the Canadian Pain Society, 2002. Pain Res Manag. 2003;8 Suppl A:3A-28A.

31. Merskey H, Bogduk N, editors. Classification of Chronic Pain: Descriptions of Chronic Pain Syndromes and Definition of Pain Terms. Seattle, WA: IASP Press; 2011.

32. Beaudry $\mathrm{N}$ [webpage on the Internet]. Les tarifs des spécialistes de la santé en 2007 [The rates of health care professionals in 2007]. Montreal, QC: Normandin Beaudry; Communiqué. 2007;10(12). Available from: http://www.normandin-beaudry.ca/publications/communiques/ archives/2007/vol10-n12.fr.html. Accessed November 4, 2013.

33. Moulin DE, Clark AJ, Gilron I, et al; Canadian Pain Society. Pharmacological management of chronic neuropathic pain-consensus statement and guidelines from the Canadian Pain Society. Pain Res Manag. 2007;12(1):13-21.

34. O'Connor AB, Dworkin RH. Treatment of neuropathic pain: an overview of recent guidelines. Am J Med. 2009;122(Suppl 10): S22-S32. 
35. Harpaz R, Ortega-Sanchez IR, Seward JF; Advisory Committee on Immunization Practices (ACIP) Centers for Disease Control and Prevention (CDC). Prevention of herpes zoster: recommendations of the Advisory Committee on Immunization Practices (ACIP). MMWR Recomm Rep. 2008;57(RR-5):1-30; quiz CE2-CE4.

36. Régie de l'assurance maladie du Québec. List of Medications. Gatineau, QC: Service des relations avec la clientele; 2011. Available from: https://www.prod.ramq.gouv.qc.ca/DPI/PO/Commun/PDF/Liste_Med/ Liste_Med/liste_med_mod1_2011_12_16_en.pdf. Accessed April 22, 2013.

37. McKesson Canada [homepage on the Internet]. McKesson Canada. San Francisco, CA: McKesson Corporation; 2013. Available from: https:// www.mckesson.ca. Accessed September 9, 2013.

38. Vigilance Santé [homepage on the Internet]. Vigilance Santé. Repentigny, QC: Vigilance Santé; 2013. Available from: http://www. vigilance.ca. Accessed September 9, 2013

39. Statistics Canada [webpage on the Internet]. Salaires horaires moyens des employés selon certaines caractéristiques et occupations, données non désaisonnalisées, par province (mensuel) (Canada). Ottawa, ON: Government of Canada; 2005. Available from: http://www.statcan. gc.ca/tables-tableaux/sum-som/102/cst02/labr69a-fra.htm. Accessed September 9, 2013.

40. Statistics Canada [webpage on the Internet]. Labour force survey estimates (LFS), by sex and detailed age group annual (persons x 1,000). Ottawa, ON: Government of Canada; 2014. Available from: http:// www5.statcan.gc.ca/cansim/a05?lang=eng\&id=2820002. Accessed September 9, 2013.

41. Commission des normes du travail du Québec [webpage on the Internet]. History of the minimum wage. Québec, QC: Commission des norms du travail Québec; Available from: http://www.cnt.gouv.qc.ca/ en/wages-pay-and-work/wages/history-of-the-minimum-wage/index. html. Accessed August 26, 2013.

42. Hu XH, Markson LE, Lipton RB, Stewart WF, Berger ML. Burden of migraine in the United States: disability and economic costs. Arch Intern Med. 1999;159(8):813-818.

43. Cleeland CS, Ryan KM. Pain assessment: global use of the Brief Pain Inventory. Ann Acad Med Singapore. 1994;23(2):129-138.

44. Tyler EJ, Jensen MP, Engel JM, Schwartz L. The reliability and validity of pain interference measures in persons with cerebral palsy. Arch Phys Med Rehabil. 2002;83(2):236-239.

45. Kosinski M, Janagap CC, Gajria K, Schein J. Psychometric testing and validation of the Chronic Pain Sleep Inventory. Clin Ther. 2007; 29 Suppl:2562-2577.

46. Zigmond AS, Snaith RP. The hospital anxiety and depression scale. Acta Psychiatr Scand. 1983;67(6):361-370.
47. Charlson ME, Pompei P, Ales KL, MacKenzie CR. A new method of classifying prognostic comorbidity in longitudinal studies: development and validation. J Chronic Dis. 1987;40(5):373-383.

48. Consumer Price Index, historical summary (1994 to 2013) [webpage on the Internet]. Ottawa: Statistics Canada, Government of Canada [updated January 24, 2014]. Available from: http:/www.statcan. gc.ca/tables-tableaux/sum-som/101/cst01/econ46a-eng.htm. Accessed May 12, 2014

49. Verstappen SM, Verkleij H, Bijlsma JW, et al. Determinants of direct costs in Dutch rheumatoid arthritis patients. Ann Rheum Dis. 2004;63(7):817-824.

50. Walen HR, Cronan PA, Bigatti SM. Factors associated with healthcare costs in women with fibromyalgia. Am J Manag Care. 2001;7 Spec No: SP39-SP47.

51. Wolfe F, Ross K, Anderson J, Russell IJ, Hebert L. The prevalence and characteristics of fibromyalgia in the general population. Arthritis Rheum. 1995;38(1):19-28.

52. Manning WG. The logged dependent variable, heteroscedasticity, and the retransformation problem. J Health Econ. 1998;17(3):283-295.

53. Fleming S, Rabago DP, Mundt MP, Fleming MF. CAM therapies among primary care patients using opioid therapy for chronic pain. $B M C$ Complement Altern Med. 2007;7:15.

54. Ekman M, Jönhagen S, Hunsche E, Jönsson L. Burden of illness of chronic low back pain in Sweden: a cross-sectional, retrospective study in primary care setting. Spine (Phila Pa 1976). 2005;30(15):1777-1785.

55. Robinson RL, Birnbaum HG, Morley MA, Sisitsky T, Greenberg PE, Claxton AJ. Economic cost and epidemiological characteristics of patients with fibromyalgia claims. J Rheumatol. 2003;30(6):1318-1325.

56. Silverman S, Dukes EM, Johnston SS, Brandenburg NA, Sadosky A, Huse DM. The economic burden of fibromyalgia: comparative analysis with rheumatoid arthritis. Curr Med Res Opin. 2009;25(4):829-840.

57. White AG, Birnbaum HG, Janagap C, Buteau S, Schein J. Direct and indirect costs of pain therapy for osteoarthritis in an insured population in the United States. J Occup Environ Med. 2008;50(9):998-1005.

58. Jacobsson LT, Lindroth Y, Marsal L, Juran E, Bergström U, Kobelt G. Rheumatoid arthritis: what does it cost and what factors are driving those costs? Results of a survey in a community-derived population in Malmö, Sweden. Scand J Rheumatol. 2007;36(3):179-183.

59. Pugner KM, Scott DI, Holmes JW, Hieke K. The costs of rheumatoid arthritis: an international long-term view. Semin Arthritis Rheum. 2000;29(5):305-320.

60. Tarride JE, Collet JP, Choinière M, Rousseau C, Gordon A. The economic burden of neuropathic pain in Canada. JMed Econ. 2006;9(1-4): $55-68$. 


\section{Supplementary materials}

Table SI Hospitalization codes related or possibly related to chronic pain

- Adhesive capsulitis of shoulder

- Algoneurodystrophy, unspecified

- Arthritis, unspecified

- Articular ankylosis

- Articular ankylosis - knee joint

- Carpal tunnel syndrome

- Cervicalgia

- Chronic intractable pain

- Chronic salpingitis and oophoritis

- Coxarthrosis, unspecified

- Endometriosis of uterus

- Endometriosis, unspecified

- Fibromyalgia

- Gonarthrosis, unspecified

- Gout, unspecified

- Idiopathic gout - elbow joint

- Idiopathic gout - hand joints

- Irritable bowel syndrome with diarrhea

- Irritable bowel syndrome without diarrhea

- Lateral epicondylitis

- Low back pain

- Osteoarthritis, unspecified

- Other cervical disc displacement

- Other dorsalgia

- Other specified arthrosis

- Other specified disorders of bone - leg

- Other specified intervertebral disc displacement

- Other specified spondylopathies - cervical region

- Pain in limb - scapular region

- Radiculopathy - dorsal region

- Rheumatoid arthritis, unspecified

- Rotator cuff syndrome

- Spinal instabilities - lumbar region

- Spinal stenosis - cervical region

- Spinal stenosis - lumbar region

- Spondylosis, unspecified - lumbar region 
Table S2 Documented analgesics

\begin{tabular}{|c|c|}
\hline Therapeutic class & International common denomination \\
\hline \multicolumn{2}{|l|}{ Anticonvulsants } \\
\hline Carboxylic acid derivatives & Valproic acid \\
\hline Gamma-aminobutyric acid analogs & Gabapentin, Pregabalin \\
\hline Iminostilbene & Carbamazepine, Oxcarbazepine \\
\hline Other anticonvulsants & Divalproex, Lamotrigine, Topiramate \\
\hline \multicolumn{2}{|l|}{ Antidepressants } \\
\hline Selective serotonin reuptake inhibitors & Citalopram, Escitalopram, Fluoxetine, Fluvoxamine, Paroxetine, Sertraline, Trazodone \\
\hline Serotonin and noradrenaline reuptake inhibitors & Duloxetine, Venlafaxine \\
\hline Tricyclic and tetracyclic antidepressants & $\begin{array}{l}\text { Amitriptyline, Clomipramine, Desipramine, Doxepin, Imipramine, Maprotiline, Mirtazapine, } \\
\text { Nortriptyline, Trimipramine }\end{array}$ \\
\hline Other antidepressants & Bupropion \\
\hline Antiretroviral & Acyclovir, Famciclovir, Valacyclovir \\
\hline Disease-modifying antirheumatic drugs & $\begin{array}{l}\text { Auranofin, Aurothioglucose, Aurothiomalate, Azathioprine, Chloroquine, Cyclosporine, } \\
\text { D-penicillamine, Hydroxychloroquine, Leflunomide, Methotrexate, Sulfasalazine }\end{array}$ \\
\hline \multicolumn{2}{|l|}{ Muscle relaxants } \\
\hline Benzodiazepine & Diazepam, Tetrazepam \\
\hline Carbamic acid derivatives & Methocarbamol \\
\hline Centrally acting myorelaxants & Cyclobenzaprine, Tizanidine \\
\hline Gamma-aminobutyric acid derivatives & Baclofen \\
\hline Other muscle relaxants & Thiocolchicoside \\
\hline \multicolumn{2}{|l|}{ Nonsteroidal antiinflammatory } \\
\hline Acetic acids & Diclofenac, Etodolac, Indomethacin, Ketorolac, Nabumetone \\
\hline \multicolumn{2}{|l|}{ Acetylsalicylic acid } \\
\hline Coxibs & Celecoxib \\
\hline Fenamates & Meclofenamate, Mefenamic acid \\
\hline Oxicams & Meloxicam, Piroxicam \\
\hline Propionic acids & Fenoprofen, Flurbiprofen, Ibuprofen, Ketoprofen, Naproxen, Oxaprozin \\
\hline \multicolumn{2}{|l|}{ Opioids } \\
\hline Agonist-antagonist derivatives & Buprenorphine, Butorphanol, Nalbuphine, Pentazocine \\
\hline Antagonists & Naloxone \\
\hline Benzomorphan derivatives & Pentazocine \\
\hline Centrally acting analgesics & Tramadol \\
\hline Meperidine-like agonists & Fentanyl, Meperidine \\
\hline Methadone-like agonists & Methadone, Propoxyphene \\
\hline Morphine-like agonists & Codeine, Hydrocodone, Hydromorphone, Levorphanol, Morphine, Oxycodone, Oxymorphone \\
\hline Natural cannabinoids & Tetrahydrocannabinol, Cannabidiol \\
\hline Synthetic cannabinoids & Dronabinol, Nabilone \\
\hline
\end{tabular}

Journal of Pain Research

\section{Publish your work in this journal}

The Journal of Pain Research is an international, peer-reviewed, open access, online journal that welcomes laboratory and clinical findings in the fields of pain research and the prevention and management of pain. Original research, reviews, symposium reports, hypothesis formation and commentaries are all considered for publication.

\section{Dovepress}

The manuscript management system is completely online and includes a very quick and fair peer-review system, which is all easy to use. Visit http://www.dovepress.com/testimonials.php to read real quotes from published authors.

\footnotetext{
Submit your manuscript here: http://www.dovepress.com/journal-of-pain-research-journal
} 